\title{
Rancang Bangun M2M (Machine-to-Machine) Communication Berbasis 6LoWPAN
}

\author{
Doni Pradana ${ }^{* 1}$, Bakhtiar Alldino Ardi Sumbodo ${ }^{2}$ \\ ${ }^{1}$ Prodi Elins. Departemen Ilmu Komputer dan Elektronika FMIPA UGM \\ ${ }^{2}$ Departemen Ilmu Komputer dan Elektronika, FMIPA UGM, Yogyakarta \\ e-mail: ${ }^{* 1}$ donipradana29@gmail.com, ${ }^{2}$ b.alldino.as@mail.ugm.ac.id
}

\begin{abstract}
Abstrak
Pada masa sekarang ini perkembangan teknologi menyediakan komunikasi tanpa menggunakan kabel yang disebut dengan teknologi nirkabel. Salah satu teknologi komunikasi nirkabel tersebut yaitu komunikasi M2M (Machine to Machine). Pada penelitian ini menggunakan protokol 6LoWPAN sebagai basis komunikasi M2M, dikarenakan pada protokol Zigbee ditemui kelemahan seperti nilai end-to-end delay dan packet loss yang lebih besar.

Pengerjaan penelitian ini adalah merancang sistem M2M communication berbasis 6LoWPAN dan membandingkan data hasil performasi dari protokol 6LoWPAN dengan protokol Zigbee dari segi end-to-end delay dan packet loss yang disertai dengan analisis terhadap sistem. Variasi pengujian adalah dengan mengatur baud rate Xbee 1200 bps, 4800 bps, 9600 bps, 19200 bps, 38400 bps, 57600 bps, 115200 bps. Selain baud rate, variasi juga dilakukan dengan mengatur jarak antar node 10 meter sampai dengan 60 dengan interval 10 meter. Waktu rata-rata end-to-end delay sebesar 1869 milidetik pada 6LoWPAN, sedangkan protokol Zigbee 422 milidetik. Dari segi packet loss, protokol 6LoWPAN tidak menyediakan packet loss dikarenakan penggunaan UDP memang tidak memiliki acknowledgement dan juga squence number untuk melacak packet loss, sedangkan protokol Zigbee menghasilkan rata-rata packet loss sebesar $26 \%$.
\end{abstract}

Kata kunci-6LoWPAN, Zigbee, Xbee, delay, packet loss

At the present time of technological development provides a communication without using cable which are called wireless technology. One of wireless communication technology is M2M (Machine to Machine) communication. In this research, using a protocol 6LoWPAN as the basis of M2M communications, becaused Zigbee protocol has weakness such as the value of end-toend delay and packet loss is greater than 6LoWPAN protocol.

Processing on this research is desaign M2M communication system based on 6LoWPAN protocol, and then compare 6LoWPAN protocol with Zigbee protocol in data performance aspect, terms of end-to-end delay and packet loss. Variations of testing is to set the baud rate Xbee 1200 bps, 4800 bps, 9600 bps, 19200 bps, 38400 bps, 57600 bps, 115200 bps. Beside of baud rate, variation also adjusting the distance between nodes from 10 meters up to 60 meters by 10 meter intervals. Average of end-to-end delay time is 1899 milliseconds on 6LoWPAN, while protocol Zigbee is 422 miliseconds. In 6LoWPAN protocol has not provided packet loss, because UDP not have an acknowledgement and squence number to track packet loss, while average of packet loss Zigbee protocol is $26 \%$.

Keywords-6LoWPAN, Zigbee,Xbee, delay, packet loss 


\section{PENDAHULUAN}

$\mathrm{P}$ ada masa sekarang ini perkembangan teknologi memungkinkan layanan komunikasi tanpa menggunakan kabel yang disebut dengan teknologi nirkabel. Salah satu teknologi komunikasi nirkabel tersebut yaitu M2M (Machine to Machine) Communication. Komunikasi M2M itu sendiri merupakan komunikasi antar dua perangkat atau lebih yang memiliki kemampuan sama lalu terhubung satu sama lain [1]. Komunikasi M2M ini juga banyak diaplikasikan untuk pemantauan suhu, kelembapan, kesehatan, hingga pengendalian jarak jauh. Komunikasi pada perangkat M2M pada saat ini banyak menggunakan media komunikasi, salah satu media yang digunakan yaitu menggunakan standar komunikasi 802.15.4. Penggunaan protokol dalam komunikasi M2M ini juga sangat diperhatikan, mengingat pada pengoperasiannya dibutuhkan kinerja yang cepat dan handal. Protokol 6LoWPAN memberikan rata-rata end-to-end delay yang lebih kecil dari pada protokol Zigbee, dengan end-to-end delay 167 milidetik pada protokol 6LoWPAN dan 392,3 milidetik pada protokol Zigbee [2].

Maka dari itu, pada penelitian ini digunakanlah protokol 6LoWPAN (IPv6 Low Power Personal Area Network) yang dikatakan lebih baik kinerjanya dari protokol Zigbee. Kinerja yang dimaksud adalah end-to-end delay dan packet loss. [3] End-to-end delay adalah waktu yang diperlukan oleh suatu paket data yang berasal dari source node hingga mencapai destination node. [4] Sedangkan packet loss merupakan parameter yang menunjukkan jumlah total paket yang hilang. Mengingat protokol Zigbee dan protokol 6LoWPAN sama-sama menggunakan standar komunikasi 802.15.4 pada PHY dan MAC layer. 6LoWPAN merupakan suatu protokol yang digunakan sebagai standar integrasi IP pada jaringan IoT (Internet of Things) yang berdaya rendah [5]. IoT adalah interkoneksi dari perangkat yang teridentifikasi secara unik dalam keberadaan infrastruktur internet [6]. Melihat hal tersebut, penelitian ini akan ditunjukkan untuk mengimplementasikan protokol 6LoWPAN pada komunikasi M2M (Machine to Machine) dalam meningkatkan kinerja yaitu dalam segi end-to-end delay dan juga packet loss.

\section{METODE PENELITIAN}

\subsection{Analisis Sistem}

Sistem yang akan dibuat terdiri dari 2 bagian yaitu rancang bangun sistem perangakat keras dan sistem perangkat lunak. Rancangan perangkat keras dari sensor node dan juga sink node menggunakan Arduino Mega 2560 sebagai microcontroler, modul sensor DHT11 untuk membaca parameter fisik yang berupa suhu dan kelembapan, dan juga modul RTC (Real Time Clock) untuk menampilkan. Dimana data dari modul sensor DHT11 dan juga RTC digunakan untuk pembuatan frame data. Sebagai komponen utama dalam melakukan komunikasi yang menyadiakan standar 802.15.4 sebagai media komunikasi dalam hal ini menggunakan Xbee Series 1 untuk penggunaan protokol 6LoWPAN dan Xbee Series 2 untuk penggunaan protokol Zigbee. Karakteristik dari 6LoWPAN adalah paket yang dikirim berukuran kecil sebesar 127 bytes, mendukung pengalamatan 16-bit atau IEEE 64-bit extended Media Access Control, bandwitdh yang kecil sebesar $250 \mathrm{kbps}$ dengan frekuensi berjalan pada rentan 2,4 GHz [7].

Proses kerja dari alat ini adalah pada kedua node yang terdiri dari sensor node dan juga sink node melakukan pembacaan parameter fisik yang berupa suhu dan juga kelembapan dengan menggunakan modul sensor DHT 11. Kedua node akan membuat frame data, pada pada sink node sama seperti pada sensor node tapi yang membedakan yaitu, pada sink node menerima paket data dari sensor node dan mengirimnya ke gateway dengan komunikasi serial USB untuk menampilkan frame data yang dikirim oleh sensor node (client) dan juga menampilkan frame 
data yang dibuat oleh sink node (server) itu sendiri. Selanjutnya, hubungan gateway dengan PC menggunakan kabel LAN (RJ45) dan juga perangkat lunak Putty, untuk mengakses gateway menggunakan SSH (Secure Shell) sebagai perintah untuk mengakses gateway. Penggunaan dari gateway hanya dibutuhkan pada pengoperasian sistem tidak digunakan pada proses pengujian yang hanya menggunakan 2 buah node. Langsung menghubungkan sink node ke laptop. Rancangan sistem ditunjukkan pada diagram blok rancangan sistem pada Gambar 1.

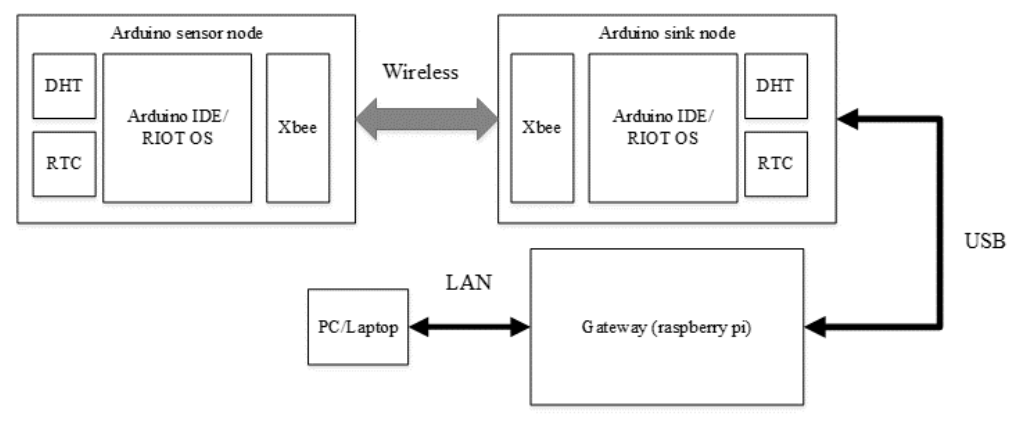

Gambar 1 Diagram blok rancangan sistem

\subsection{Rancangan Perangkat Keras}

Rancangan perangkat keras dari sensor node dan juga sink node menggunakan Arduino Mega 2560 sebagai microcontroler, modul sensor DHT11 untuk membaca parameter fisik yang berupa suhu dan kelembapan, dan juga modul RTC (Real Time Clock) untuk menampilkan . Dimana data dari modul sensor DHT11 dan juga RTC digunakan untuk pembuatan frame data. Sebagai komponen utama dalam melakukan komunikasi yang menyadiakan standar 802.15.4 sebagai media komunikasi dalam hal ini menggunakan Xbee Series 1 untuk penggunaan protokol 6LoWPAN dan Xbee Series 2 untuk penggunaan protokol Zigbee, kedua modul Xbee sama-sama dihubungkan dengan Xbee Adapter yang dihubungkan dengan pin RX, TX, vcc $+5 \mathrm{~V}$, GND (ground). Semua komponen yang terdiri dari modul DHT 11, modul RTC, dan Xbee Adapter akan dihubungkan dengan pin mikrokontroler Arduino Mega 2560 dengan menggunakan pcb yang didesain seperti shield. Skematik pcb sesuai pada Gambar 2.

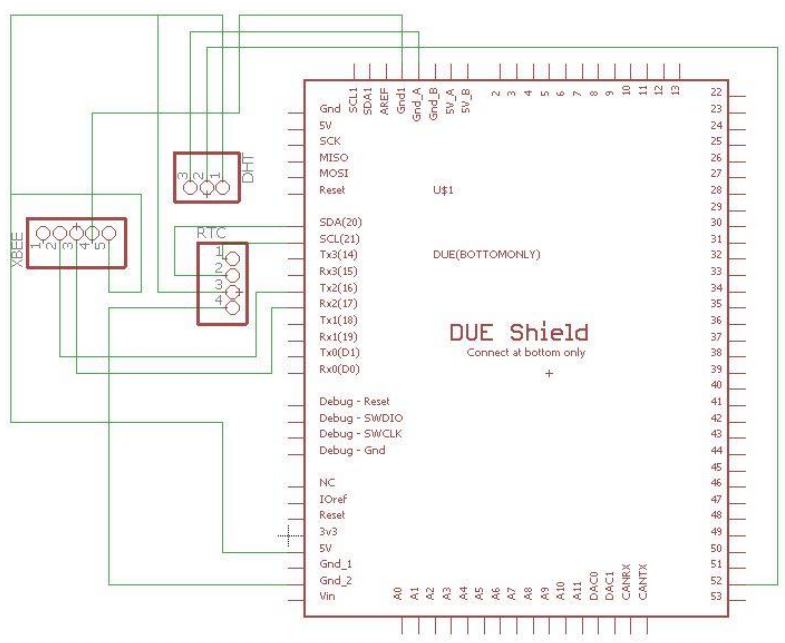

Gambar 2 Skematik pcb

\subsection{Rancangan Perangkat Lunak}

Rancangan perangkat lunak, meliputi pemograman menggunakan bahasa $\mathrm{C}++/ \mathrm{C}$ untuk membuat RIOT OS dan juga membuat program pada Arduino IDE yang akan ditanamkan ke 
dalam Arduino board. Pada proses penanaman program pada mikrokontroler Arduino Mega 2560 menggunakan perintah upload pada Arduino IDE dan perintah make flash all term pada RIOT OS yang sebelumnya dilakukan compile menggunakan compiler gcc, kedua perangkat lunak tersebut di-install pada laptop yang menggunakan sistem operasi Ubuntu 14.10 LTS dan juga Windows 10. Kedua program tersebut akan ditanamkan secara bergantian sesuai dengan penggunaan untuk pengujian, jika ingin melakukan pengujian terhadap protokol Zigbee akan menanamkan program dengan Arduino IDE, jika ingin melakukan pengujian terhadap protokol 6LoWPAN akan menanamkan program RIOT OS. Membuat frame data yang menjadi acuan data yang dikirimkan, pengalamatan node menggunakan Ipv6 yang berjenis unicast link-local address. Selain itu, rancangan pada gateway untuk menerima data secara serial dengan USB dari sink node yang bertujuan untuk dapat diakses menggunakan perangkat komputer atau pada jaringan komputer. Penggunaan gateway sebagai akses terhadap serial monitor untuk memantau proses penguriman dan penerimaan frame data pada laptop atau pada jaringan, peran gateway ini juga bisa dimaksud sebagai ethernet shield Arduino Mega 2650 untuk memungkinkan akses terhadap jaringan komputer dan juga PC (Personal Computer). Perangkat lunak yang terdapat pada gateway dalam hal ini adalah Raspberry Pi adalah sistem operasi Raspbian yang merupakan sistem operasi default atau bawaan pada Raspberry Pi. Pengaturan pada sistem operasi Raspbian hanya SSH (Secure Shell) dengan tujuan untuk dapat mengakses Raspberry Pi.

Rancangan dan pemograman komunikasi protokol 6LoWPAN dengan RIOT OS menggunakan perangkat lunak Gedit dan compiler gcc pada Ubuntu 14.04 LTS. Pemograman untuk pembentukan Operating System RIOT OS sudah disediakan pustaka dari pengembang, sehingga hanya menggabungkan pustaka dan pemograman yang sederhana. Pemograman dibagi menjadi 2 yaitu, rancangan sensor node dan juga sink node yang bertindak sebagai server dan juga client. Gambar 3 menunjukkan diagram alir proses pengiriman langsung frame data pada sensor node atau client menuju ke sink node atau server.

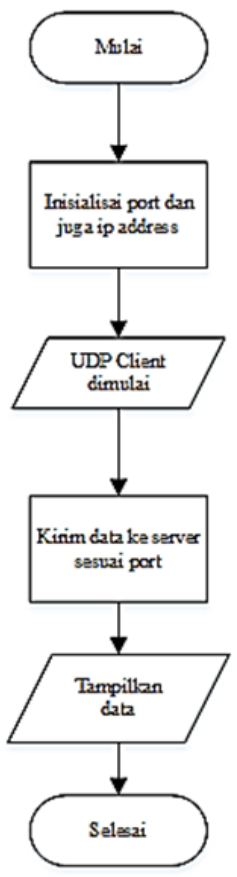

Gambar 3 Diagram alir sensor node protokol 6LoWPAN

Pemograman 6LoWPAN dilakukan dengan mengacu pada proses pengiriman UDP yang hanya mengirimkan frame data yang dibuat secara terus-menerus. Sink node akan langsung dihubungkan dengan laptop tidak melalui gateway pada proses pengujian berlangsung. Progam dimulai dengan menginisialisasi dari port client dan juga port server sebagai tujuan pengiriman data, selain itu ip address juga diinisialisasi untuk mengetahui alamat dari node client. 
Selanjutnya mencetak UDP client untuk mengetahui program sudah berjalan apa belum. Proses dilanjutkan dengan dikirimnya frame data dari sensor node atau client menuju ke sink node atau server. Pengiriman data harus sesuai dengan port tujuan. Data yang dikirim akan ditampilkan dengan tujuan mengetahui data keberapa yang dikirim, dikarenakan program UDP ini mengirimkan data secara terus menerus. Diagram alir pada Gambar 4 merupakan diagram alir dari sink node atau server. Menunjukkan proses yang diawali sama seperti pada node client, yaitu dengan menginisialisasi port dan juga ip address dari server. Selanjutnya mencetak tulisan yang menunjukkan bahwa server sudah siap untuk menerima data dari client. Proses selanjutnya adalah menerima frame data dari sensor node atau cient. Jika frame data diterima, data akan ditampilkan pada sink node atau server, jika tidak sink node atau server akan menunggu sampai ada data yang diterima.

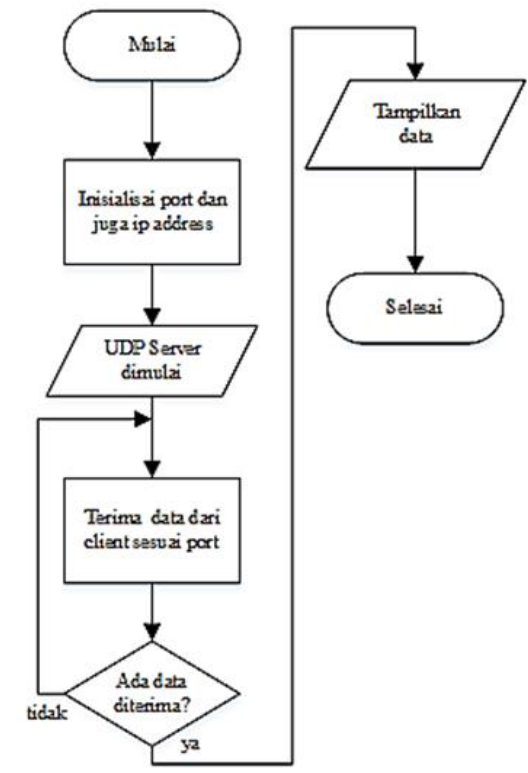

Gambar 4 Diagram alir sink node protokol 6LoWPAN

Rancangan dan pemograman sistem dari komunikasi protokol Zigbee menggunakan perangkat lunak Arduino IDE dibagi menjadi 2 yaitu, rancangan sensor node dan juga sink node. Gambar 5 merupakan diagram alir sensor node dengan proses kerja yang sederhana yaitu dimulainya pembuatkan data frame untuk dikirimkan ke sink node. Setelah dibuatkan frame data, selanjutnya melakukan pengiriman frame data dengan cara menampilkan pada serial monitor, secara otomatis akan terkirim melalui komunikasi serial Xbee.

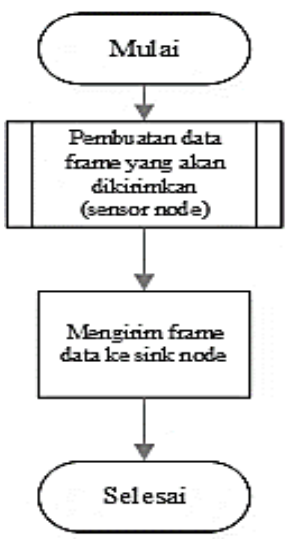

Gambar 5 Diagram alir sensor node protokol Zigbee 
Rancangan pada sink node sama seperti sensor node yaitu membuat frame data. Selanjutnya, sink node akan menunggu data dari sensor node, jika sink node sudah mendapatkan data dari sensor node maka selanjutnya akan diproses, jika tidak maka akan mencari terus sampai mendapatkan data dari sensor node. Dikarenakan zigbee merupakan protokol yang bisa dirancang maka, proses memeriksa sesuai apa tidak panjang frame data sepanjang 29 byte, jika sesuai akan ditampilkan di serial monitor sink node bersamaan dengan frame data dari sink node, jika tidak maka akan menampilkan "Request Time Out" yang menjadi acuan jika data yang diterima kurang dari 29 byte atau cacat dengan mengulangnya sampai mendapatkan data yang sesuai dengan panjang 29 byte. Proses selanjutnya menampilkan frame data dari sensor node dan juga dari sink node. Selain itu, menampilkan juga waktu pada gateway untuk mengetahui besaran delay pada protokol Zigbee. Gambar 6 merupakan diagram alir dari sink node.

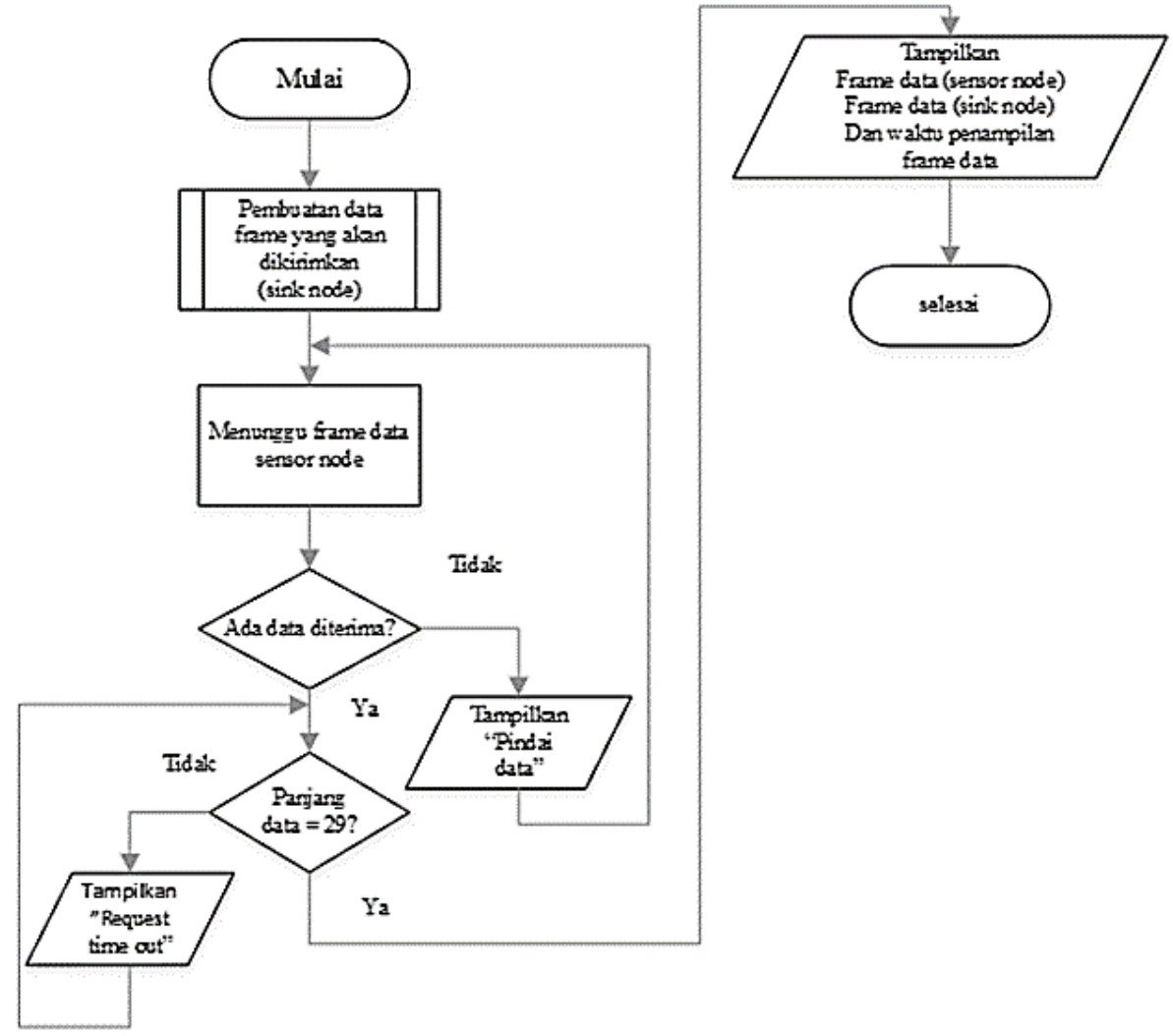

Gambar 6 Diagram alir sink node protokol Zigbee

Frame data yang digunakan pada pengiriman dan penerimaan dibuat sendiri yang terdiri dari bagian header, separator, source node, destination node, dan data sensor DHT dan RTC. Format data yang dikirim pada bagian pemancar (sensor node) dan penerima (sink node) menggunakan header " $H$ " yang menunjukkan bahwa setiap frame data dimulai dengan " $H$ ", serta setiap parameter dipisahkan dengan tanda "\#" untuk mengetahui frame data secara terpisah, dan diakhiri dengan tanda "!" yang menunjukkan bahwa frame data akan berakhir. Susunan dari frame data merupakan susunan yang dibuat sendiri dengan alasan dapat melihat besaran suhu, kelembapan, dan juga waktu yang ditunjukan pada saat proses pengiriman dan penerimaan data berlangsung, dengan adanya pemisah dan juga mengetahui awal dan akhir dari frame data, panjang data yang dikirimkan adalah sebesar 29 byte. Tabel 1 menjelaskan susunan dari frame data yang digunakan dan dibuat sendiri.

Perancangan juga dilakukan pada pengalamatan kedua node yang menggunakan ipv6 dengan format link-local unicast dikarenakan komunikasi dilakukan secara point-to-point secara 
langsung antara dua node dalam suatu jaringan. Penggunaan IPv6 sebagai pengalamatan merupakan hal yang penting pada 6LoWPAN. Pengalamatan pada IPv6 memiliki panjang 128 bit dan terbagi atas 64 bit prefix dan 64 bit interface Identifier (IID) [8]. Dengan ketentuan fe80: : /10 atau memiliki sepuluh bit alamat prefix, dan sisa panjang alamat akan mengacu pada serial number pada Xbee.

Tabel 1 Format frame data

\begin{tabular}{|c|c|c|c|c|}
\hline \multirow{2}{*}{$\begin{array}{l}\text { Data } \\
\text { ke- }\end{array}$} & \multicolumn{2}{|c|}{ Sensor node } & \multicolumn{2}{|c|}{ Sink node } \\
\hline & Keterangan & Nilai & Keterangan & Nilai \\
\hline 1 & Header & $\mathrm{H}$ & header & $\mathrm{H}$ \\
\hline 2 & Pemisah & \# & pemisah & \# \\
\hline 3 & ID (sensor node) & 1 & $\mathrm{ID}(\operatorname{sink}$ node $)$ & 2 \\
\hline 4 & Pemisah & \# & pemisah & \# \\
\hline 5 & pengukuran DHT 11 & (suhu) & pengukuran DHT 11 & (suhu) \\
\hline 6 & Pemisah & \# & pemisah & $\#$ \\
\hline 7 & pengukuran DHT 11 & (kelembapan) & pengukuran DHT 11 & (kelembapan) \\
\hline 8 & Pemisah & \# & pemisah & \# \\
\hline 9 & nilai RTC & (thn) & nilai RTC & (thn) \\
\hline 10 & Pemisah & $\#$ & pemisah & $\#$ \\
\hline 11 & nilai RTC & (bln) & Nilai RTC & (bln) \\
\hline 12 & Pemisah & $\#$ & pemisah & $\#$ \\
\hline 13 & nilai RTC & $(\operatorname{tgl})$ & nilai RTC & $(\operatorname{tgl})$ \\
\hline 14 & Pemisah & \# & pemisah & \# \\
\hline 15 & nilai RTC & (jam) & nilai RTC & (jam) \\
\hline 16 & Pemisah & \# & pemisah & \# \\
\hline 17 & nilai RTC & (menit) & nilai RTC & (menit) \\
\hline 18 & Pemisah & \# & pemisah & $\#$ \\
\hline 19 & nilai RTC & (detik) & nilai RTC & (detik) \\
\hline 20 & Pemisah & \# & pemisah & $\#$ \\
\hline 21 & Akhir & $!$ & akhir & $!$ \\
\hline
\end{tabular}

\subsection{Implementasi}

Gambar 7 merupakan gambar sensor node dan juga sink node yang telah diimplementasikan. Tiap node terdiri dari mikrokontroler Arduino Mega 2560, Xbee, modul sensor DHT11, dan juga RTC.

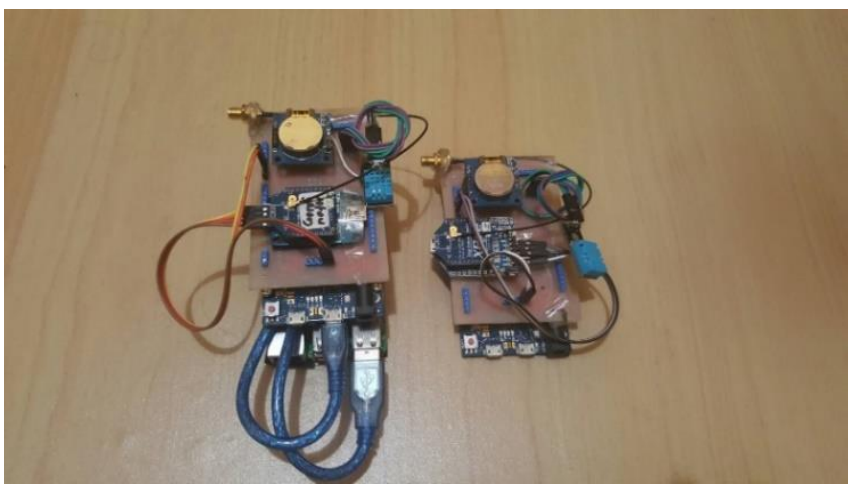

Gambar 7 sensor node dan sink node

\section{HASIL DAN PEMBAHASAN}

Rencana pengujian dibagi menjadi 3 yaitu, pengujian kekuatan sinyal pada Xbee, pengujian komunikasi dengan protokol Zigbee, dan pengujian komunikasi dengan protokol 6LoWPAN . Pengujian signal strength atau melihat kekuatan sinyal antar Xbee (RSSI) . RSSI (Received Signal Strength Indication) adalah sebuah ukuran kekuatan sinyal radio yang diterima 
oleh receiver dengan kata lain dapat mengetahui besar kemampuan sejauh mana transmitter dan receiver dalam melakukan komunikasi [9]. Jarak yang diuji adalah sama seperti pengujian komunikasi protokol yaitu, 10 sampai dengan 60 meter dengan interval 10 meter, jarak. Pemilihan jarak ini merupakan asumsi dari jarak efektif yang bisa dilakukan oleh perangkat Xbee. Pengujian RSSI menggunakan 2 jenis node yaitu, local node dan juga remote node, maksud dari node ini adalah modul Xbee bukan menggunakan node yang menggunakan Arduino Mega 2560. Perangkat Xbee yang digunakan adalah perangkat Xbee S2 dengan asumsi hasil RSSI dari Xbee S1 sama, dikarenakan dilakukan pada tempat dan jarak yang sama dengan pengujian komunikasi protokol. Dimaksud dengan local node adalah node yang akan mengirimkan dan menrima paket data, sedangkan remote node merupakan node yang meneruskan dan mengembalikan menuju local node paket data yang sudah dikirimkan oleh local node. Pada local node menggunakan mode API (Application Programming Interface), sedangkan remote node menggunakan mode Transparrent (AT). Perangkat Xbee bekerja pada gelombang 2,4 GHz dan bekerja sama dengan sinyal Wi-Fi, maka dari itu interferensi gangguan terhadap pengujian RSSI berpengaruh. Pada Gambar 8 mengilustrasikan pengujian RSSI Xbee.

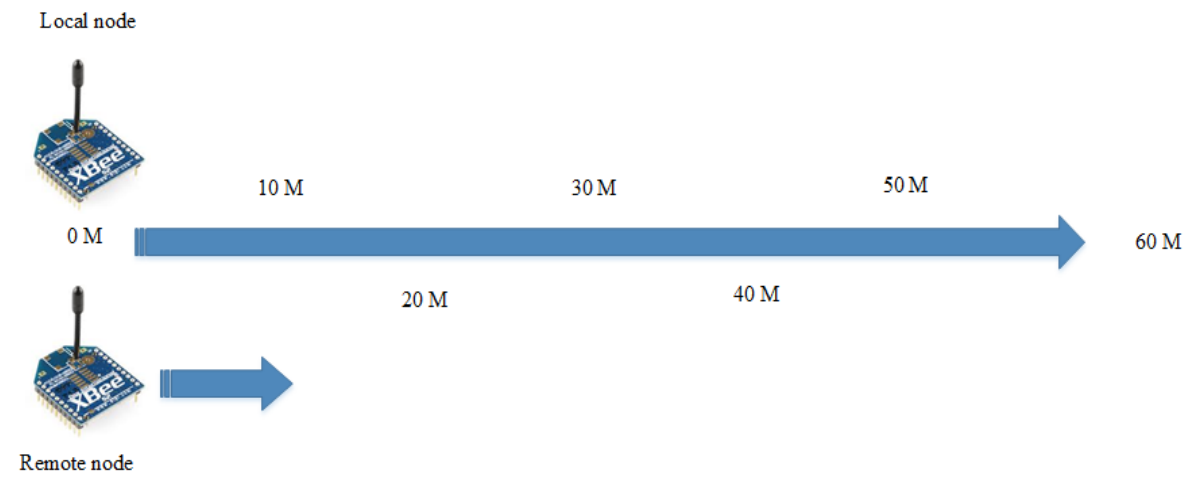

Gambar 8 Ilustrasi pengujian RSSI Xbee

Pengujian dilakukan di perangkat lunak XCTU yang merupakan perangkat lunak khusus disediakan oleh Digi Software yang merupakan perusahaan pembuatan Xbee. Dengan tools yang disediakan dapat langsung mengetahui besar dari RSSI dengan satuan $\mathrm{dBm}$.

Pengujian komunikasi dibagi menjadi 2 yaitu, pengujian komunikasi dengan protokol 6LoWPAN dan komunikasi dengan protokol Zigbe. Pegujian dilakukan dengan melihat nilai end to end delay dan packet loss. End-to-end delay adalah waktu yang diperlukan oleh suatu paket data yang berasal dari soure node hingga mencapai destination node. Dalam hal ini ini source node merupakan sensor node dan destination node merupakan sink node. Pengertian packet loss merupakan banyaknya paket yang hilang atau tidak diterima selama proses pengiriman dari source node ke destination node. Perhitungan packet loss menggunakan rumus yang terdapat pada persamaan (1).

$$
\text { Packet loss }=\frac{(a-b)}{b} \times 100 \%
$$

$\mathrm{a}=$ paket data yang tekirim $\mathrm{b}=$ paket data yang diterima

Pegujian komunikasi dilakukan dengan memberikan variasi pada jarak dan juga baudrate. Jarak yang diberikan pada pengujian sebesar 10 meter sampai dengan 60 meter dengan interval sebesar 10 meter, sedangkan pada baud rate yang diujikan sebesar 1200 bps,4800 bps,9600 bps, 19200 bps,38400 bps,56900 bps, dan 115200 bps. Pengujian ini dilakukan 7 skenario, dengan mengacu pada baud rate dan pada masing-masing baud rate akan ada variasi jarak yang sudah dijelaskan sebelumnya. Selama dilakukan pengujian terhadap komunikasi protokol tidak menggunakan gateway, tetapi langsung mengubungkan sink node langsung ke laptop. Alasan tidak menggunakan gateway pada pengujian adalah fungsi dari gateway hanya sebagai ethernet 
shield atau hanya melakukan monitoring terhadap proses pengiriman dan penerimaan data dari komputer atau jaringan dengan menggunakan fungsi dari SSH tidak termasuk kedalam salah satu pengujian terhadap komunikasi pada kedua protokol. Gambar 9 merupakan ilustrasi dari pengujian komunikasi protokol Zigbee dan protokol 6LoWPAN.

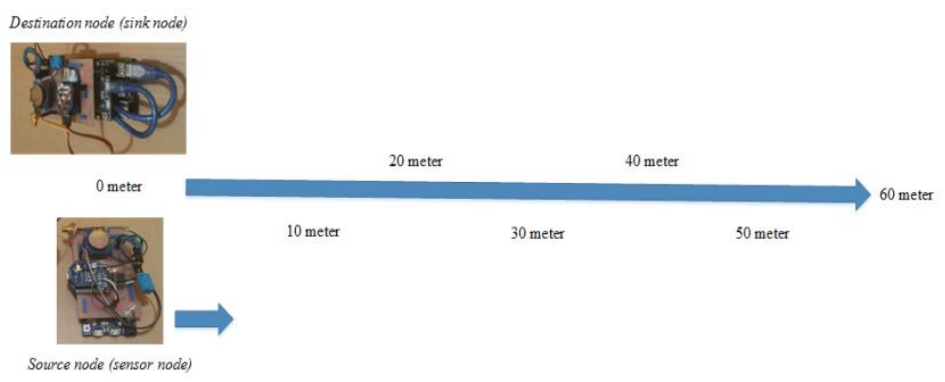

Gambar 9 Ilustrasi pengujian komunikasi protokol

Pada pengujian komunikasi protokol 6LoWPAN digunakan perangkat lunak Wireshark yang merupakan perangkat lunak yang akan merekam semua proses pengiriman dan penerimaan data. Protokol UDP, tidak menyediakan packet loss, dikarenakan tidak menyediakan acknowledgement dan juga squence number [10]. Pengujian protokol Zigbee menggunakan serial monitor dari perangkat lunak Arduino IDE yang menampilkan aktifitas pengiriman dan penerimaan data. Pendeteksian packet loss pada pengujian protokol Zigbee akan terlihat pada serial monitor dengan menampilkan "Request Time Out" yang menunjukan data yang diterima memiliki panjang data kurang dari 29 byte.

Pada hasil proses kerja alat dibahas berjalannya alat dari awal proses, pengiriman data penerimaan data. Pada Gambar 10 dan Gambar 11 merupakan proses awal dari berjalannya program sensor node dan juga sink node. Proses kerja alat hanya terfokus pada 6LoWPAN.

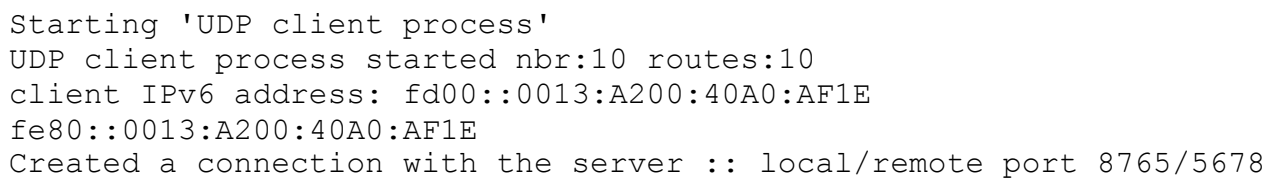

Gambar 10 Proses awal pada sensor node 6LoWPAN

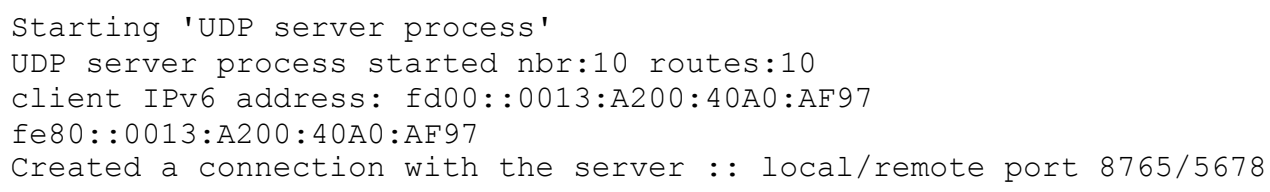

Gambar 11 Proses awal pada sink node 6LoWPAN

Pada Gambar 12 merupakan proses pengiriman frame data dari sensor node menuju sink node, sedangkan pada Gambar 13 merupakan proses penerimaan frame data dari sensor node menuju sink node.

DATA dikirim ke 2 'H\#1\#bb\#cc\#dd\#ee\#ff\#gg\#hh\#ii\#!'
DATA dikirim ke 2 'H\#1\#bb\#cc\#dd\#ee\#ff\#gg\#hh\#ii\#!'

DATA dikirim ke 2 'H\#1\#bb\#cc\#dd\#ee\#ff\#gg\#hh\#ii\#!'

Gambar 12 Pengiriman frame data pada sensor node 
DATA diterima 'H\#1\#bb\#cC\#dd\#ee\#ff\#gg\#hh\#ii\#!'dari 1

DATA diterima 'H\#1\#bb\#cc\#dd\#ee\#ff\#gg\#hh\#ii\#!'dari 1

DATA diterima 'H\#1\#bb\#cc\#dd\#ee\#ff\#gg\#hh\#ii\#!'dari 1

Gambar 13 Penerimaan frame data pada sink node

Hasil pengujian dari protokol 6LoWPAN yang dibandingkan dengan protokol Zigbee dari segi end-to-end delay dan juga packet loss dari 7 skenario menurut baud rate dan juga jarak. Tabel 2 dan Tabel 3 merupakan hasil dari pengujian end-to-end delay dari kedua protokol.

Tabel 2 Hasil pengujian end-to-end delay protokol 6LoWPAN

\begin{tabular}{|c|c|c|c|c|c|c|}
\hline \multicolumn{7}{|c|}{ end-to-delay 6LoWPAN (milidetik) } \\
\hline $\begin{array}{c}\text { Baud rate } \\
1200 \mathrm{bps}\end{array}$ & 10 meter & 20 meter & 30 meter & 40 meter & 50 meter & 60 meter \\
\hline $4800 \mathrm{bps}$ & 1720 & 1784 & 1923 & 1775 & 2136 & 2067 \\
\hline $9600 \mathrm{bps}$ & 2153 & 2168 & 2226 & 2594 & 2419 & 1941 \\
\hline $19200 \mathrm{bps}$ & 2396 & 2396 & 1859 & 1915 & 1908 & 1872 \\
\hline $34800 \mathrm{bps}$ & 2623 & 2024 & 2000 & 2152 & 2116 & 2183 \\
\hline $57600 \mathrm{bps}$ & 1079 & 174 & 1056 & 1545 & 1051 & 1153 \\
\hline $115200 \mathrm{bps}$ & 2066 & 1763 & 1770 & 1782 & 1494 & 1538 \\
\hline
\end{tabular}

Tabel 3 Hasil pengujian end-to-end delay protokol Zigbee

\begin{tabular}{|c|c|c|c|c|c|c|}
\hline \multicolumn{7}{|c|}{ end-to-delay Zigbee (milidetik) } \\
\hline $\begin{array}{c}\text { Jarak } \\
\text { Baud rate }\end{array}$ & \multirow{2}{*}{10 meter } & 20 meter & 30 meter & 40 meter & 50 meter & 60 meter \\
\hline $1200 \mathrm{bps}$ & 167 & 326 & 365 & 171 & 114 & 628 \\
\hline $4800 \mathrm{bps}$ & 273 & 70 & 368 & 161 & 368 & 549 \\
\hline $9600 \mathrm{bps}$ & 499 & 254 & 150 & 592 & 185 & 349 \\
\hline $19200 \mathrm{bps}$ & 147 & 287 & 238 & 336 & 1085 & 658 \\
\hline $34800 \mathrm{bps}$ & 141 & 233 & 212 & 137 & 181 & 198 \\
\hline $57600 \mathrm{bps}$ & 1079 & 174 & 1056 & 1545 & 1051 & 1153 \\
\hline $115200 \mathrm{bps}$ & 334 & 421 & 445 & 154 & 252 & 602 \\
\hline
\end{tabular}

Sedangkan pada hasil packet loss, protokol 6LoWPAN tidak menyediakan packet loss dikarenakan tidak menyediakan squence number dan juga acknowledgement. Protokol Zigbee memiliki packet loss yang terdapat pada Tabel 4.

Tabel 4 Packet loss protokol Zigbee

\begin{tabular}{|c|c|c|c|c|c|c|}
\hline \multicolumn{7}{|c|}{ Packet loss Zigbee (\%) } \\
\hline $\begin{array}{c}\text { Jaud rate } \\
\text { Barak }\end{array}$ & \multirow{2}{*}{10 meter } & 20 meter & 30 meter & 40 meter & \multirow{2}{*}{50 meter } & \multirow{2}{*}{60 meter } \\
\hline $4800 \mathrm{bps}$ & 0 & 0 & 53 & 20 & 60 & 13 \\
\hline $9600 \mathrm{bps}$ & 20 & 20 & 13 & 40 & 13 & 60 \\
\hline $19200 \mathrm{bps}$ & 20 & 40 & 7 & 27 & 40 & 13 \\
\hline $34800 \mathrm{bps}$ & 0 & 27 & 7 & 13 & 40 & 53 \\
\hline $57600 \mathrm{bps}$ & 47 & 33 & 13 & 20 & 60 & 47 \\
\hline $115200 \mathrm{bps}$ & 13 & 13 & 20 & 20 & 13 & 13 \\
\hline
\end{tabular}

Analisis terhadap sistem adalah pemilihan terhadap variasi terhadap baud rate dan juga jarak antar node. Pada baud rate hubungannya adalah pada penggunaan Xbee, dimana Xbee akan dihubungkan dengan mikrokontroler Arduino Mega 2560 melalui komunikasi serial. Pengaruh end-to-end delay dengan baud rate, jika menggunakan baud rate yang kecil akan 
menghasikan end-to-end delay yang besar, sebaliknya jika menggunakan baud rate yang besar akan menghasilkan end-to-end delay yang kecil, dikarenakan peran UART untuk menerjemahkan bit-bit serial menjadi data yang utuh akan mengalami perlambatan dan menghasilkan end-to-end yang besar jika menggunakan baud rate yang kecil, sebaliknya UART yang menerjemahkan bit-bit serial akan mengalami percepatan pada proses pengiriman data sehingga menghasilkan delay yang kecil. Hubungan jarak dengan delay adalah pengaruh dengan RSSI (Received Signal Strenght Indication), semakin jauh maka akan menghasilkan delay yang begitu besar, pengaruh juga pada interferensi terhadap sistem dikarenakan pengujian dilakukan di lingkungan kampus maka akan menghasilkan delay yang tidak menentu. Pada 6LoWPAN menggunakan UDP (User Datagram Protocol) dengan melakukan komunikasi secara sederhana dengan makenisme yang sangat minimal. Sederhana yang dimaksud adalah pada UDP komunikasi hanya mengirimkan data secara terus menerus tanpa adanya komunikasi awal [11], memang penggunaan UDP dirasa tepat untuk mengirimkan informasi atau data yang lebih menekankan kecapatan. Hasil yang didapat menunjukkan bahwa Zigbee memiliki waktu delay yang kecil, dikarenakan protokol Zigbee merupakan protokol, yang lebih sederhana dari pada protokol 6LoWPAN yang tidak memiliki transport layer pada OSI layer [12]. Semua proses pengiriman dan penerimaan data mengacu pada OSI layer dari application layer hingga PHY layer.

Dari segi packet loss, seperti sebelumnya yang dijelaskan bahwa 6LoWPAN tidak menyediakan packet loss, dikarenakan tidak memiliki acknowledgement dan juga sequence number untuk mendeteksi packet loss. Protokol Zigbee merupakan protokol yang dalam pengoperasiannya dapat dikembangkan dan dirancang, sehingga dapat mendeteksi packet loss. Hubungan packet loss terhadap pengujian adalah pada baud rate yang berhubungan dengan UART yang bertugas sebagai menerjemahkan bit-bit serial menjadi data yang utuh, jika menggunakan baud rate yang kecil maka akan menghasilkan packet loss yang kecil dikarenakan UART akan menerjemahkan dengan pelan dan menghasilkan error pada saat penerjemahannya kecil, sebaliknya jika menggunakan baud rate yang besar akan menghasikan error yang besar pada saat menerjemahkan dan mengakibatkan packet loss besar. Pengaruh jarak sama seperti delay akan menghasilkan data yang tidak menentu dan mengakibatkan packet loss.

Hasil dari RSSI (Received Signal Strenght Indicationi) menunjukan bahwa jarak maksimal adalah 60 meter, sistem masih bisa berjalan pada jarak antara source node dan juga destination node sampai dengan jarak 60 meter. Tabel 5 merupakan hasil pengukuran dari RSSI.

Tabel 5 Hasil pengukuran RSSI

\begin{tabular}{|c|c|}
\hline Jarak (meter) & Persentase (\%) \\
\hline 10 & 60,1 \\
\hline 20 & 50,2 \\
\hline 30 & 44,0 \\
\hline 40 & 39,8 \\
\hline 50 & 36,8 \\
\hline 60 & 33,5 \\
\hline
\end{tabular}

\section{KESIMPULAN}

Berdasarkan hasil penelitian dan juga hasi pengujian terhadap sistem perangkat lunak dan perangkat keras, maka dapat diambil kesimpulan sebagai berikut:

1. 6LoWPAN memberikan dukungan protokol jaringan IPv6 pada sensor node dan juga sink node, yang terdiri dari:

- Memiliki rata-rata end-to-end delay dari semua skenario sebesar 1879 milidetik yang lebih besar dari protokol Zigbee yang hanya sebesar 422 milidetik.

- Protokol 6LoWPAN tidak menyediakan packet loss dikarenakan menggunakan UDP (User Datagram Protocol) yang tidak memiliki pengkoreksian packet loss 
seperti acknowledgement dan juga squence number. Sedangkan protokol Zigbee memiliki rata-rata packet loss sebesar $26 \%$.

- Mengirim pesan yang berupa frame data secara unicast.

2. Kemampuan yang dimiliki oleh sistem terdiri dari:

- Jarak maksimal antara sensor node dengan sink node yaitu 60 meter.

- Dapat mengirimkan frame data sepanjang 29 byte dari sensor node menuju sink node.

\section{SARAN}

Penelitian yang telah dilakukan masih memiliki beberapa kekurangan dan memungkinkan untuk dilakukan pengembangan labih lanjut. Diantaranya:

1. Menggunakan TCP pada transport layer 6LoWPAN guna mendapatkan koneksi yang handal agar bisa mendeteksi paket yang hilang (packet loss).

2. Menggunakan format pengiriman multicast atau broadcast pada proses pengiriman data berlangsung.

\section{DAFTAR PUSTAKA}

[1] Sang-Joong, J.,2013,Personal Machine-to-Machine (M2M) Healthcare System with Mobile Device in Global Networks, Department of Electrical Engineering Universitatis Ouluensis, Oulu.

[2] Toscano, E. dan Bello, L. L., 2012, Comparative assessment of IEEE 802.15.4/Zigbee and 6LoWPAN for low-power industrial WSN in realistic scenarios, IEEE 9th International Workshop on Factory Communication, Lemgo, NRW, 21-24 Mei 2012.

[3] Abdullah, H.,Juhana,T.,Lidyawati,L., 2013, Simulasi dan Analisis Transmisi Video Streaming pada Jaringan Wifi dengan Menggunakan Opnet Modeler 14.5, Jurnal Online Institut Teknologi Nasional, No.1, Vol.1 57-67.

[4] Bobanto, W. S.,2015, Analisis Kualitas Layanan Jaringan Internet, e-journal Teknik Elektro dan Komputer, No.1, Vol.4 80-87.

[5] Ele, L.S.,Kothari, Rao, M.,2014, 6LoWPAN Based Wireless Sensor Network to Monitor Temperature, International Journal of Advanced Electronics and communication Engineering, No 1, Vol 1 1-6.

[6] Sulistyanto, M. P. dan Nugraha, D. A,2015, Implementasi IoT (Internet of things) dalam pembelajaran di Universitas Kanjuhuran Malang, SMARTICS Journal,No.1, Vol.1 20-23.

[7] Latre, B.,Pieter De, M., 2006, Throughput and Delay Analysis of Unslotted IEEE 802.15.4., Journal of Network, No.1, Vol.1 20-28

[8] Sakhtivel,C. dan Kalaiprasath,R., 2016, COMPARATIVE REVIEW ON INTERNET PROTOCOL VERSION 6 (IPV6), International Journal of Advanced Research, No.2, Volume 4 1076-1078.

[9] Palaha, Fadli. dan Zaini, 2014, PROPAGASI INDOOR GELOMBANG RADIO PERANGKAT XBEE, Jurnal Nasional Teknik Elektro, No.2, Vol.3 148-156.

[10] Behrouz A. Forouzan, 2007, Data Comunications And Networking, Ed.4, Mc Graw Hill.

[11] Sarma, P.M., 2013, Performance Measurement of TCP and UDP Using Different Queuing Algorithm in High Speed Local Area Network, Internatinal Journal of Future Computer and Communication, No 6, Vol. 2 682-686.

[12] Vishwakerma, D.D., 2012, IEEE 802.15.4 and ZigBee: A Conceptual Study, International Journal of Advance Research In Computer and Communication Engineering,No 7, Vol 1 477-480. 